\title{
Information load, time spent, and risk taking in complex decision making'
}

\author{
SIEGFRIED STREUFERT and SUSAN C. STREUFERT, \\ Purdue University, Lafayette, Ind. 47907
}

The effect of the quantity of information which decision makers receive per unit time and the effect of the length of time spent in decision-making groups on the degree of risk taking in decision making were examined. A simulated decision-making task of some complexity was used for data collection to permit comparison with results obtained in simpler laboratory settings. It was found that risk taking increases with time spent in decision making and reaches highest levels under optimal information conditions. Parallels to studies in simpler environments were examined.

In recent years, psychologists have been widely concerned with the risk-taking and the risky-shift phenomena. Several theoretical views (e.g., Kogan \& Wallach, 1964; Brown, 1965; Rettig, 1966; Pruitt, 1962), as well as considerable research, have been presented. Most of the research, whether quantitative in orientation (e.g., Edwards, 1953, 1954; Coombs \& Pruitt, 1960) or designed as an analysis of social-personality contexts (e.g., Wallach, Kogan, \& Bem, 1962; Rettig, 1966), has utilized small-scale (e.g., gambling) tasks, where Ss were either operating as advisors with little or nothing to lose or to gain, or were able to win small sums of money by playing against the "strategy" of another team or against a program. Little research concerned with more "real" situations has been reported. In this study, an initial attempt was made to collect information on risk-taking variables in more complex decision-making tasks.

Obtaining quantifiable risk-taking data for complex situations, which contain several underlying dimensions, does present some difficulty. In such settings, definitions of "risky" decision making, and quantifications of such decisions into ordinal or interval scales on which the degree of risk or the amount of risky shift can be measured, are difficult to achieve. An opportunity for a first step in this direction was presented in the Tactical Game simulation of Streufert, Clardy, Driver, Karlins, Schroder, \& Suedfeld (1965). This game utilizes an analysis of decision making in response to a preprogrammed environment. Decisions are made on a single task dimension (military operations), although the decisions may be based on multidimensional cognitions. The programmed environment permits experimenter induction of an independent variable of his choice (a manipulation possible only in this form of "experimental" simulation). Quantifiable analyses of decisions and decision-making patterns (cf. Streufert \& Schroder, 1965; Streufert, Suedfeld, \& Driver, 1965; Streufert, Driver, \& Haun, 1967; Streufert \& Driver, 1967) permit identification and quantification of risky decisions and of the degrte of sisk involved.

In this study we were concerned with the analysis of risky decision making in complex situations from two different points of view: (1) What was the effect of time spent in decision making on risk taking, and (2) what was the effect of optimal vs sub- or superoptimal information load (quantity of information per unit time) on risk taking. The first of these questions permitted a comparison of the present experimental environment with more simple environments. Davis, Hoppe, \& Hornseth (1968) researched risk taking over time (there six blocks of 10 trials) in a gambling task. Could their results be replicated in this more complex environment? The second question was concerned with the work of Streufert \& Schroder
(1965) and Streufert \& Driver (1967) based on complexity theory (Driver \& Streufert, 1966; Schroder, Driver, \& Streufert, 1967; Streufert \& Driver, 1967). These researchers demonstrated that decision making is optimal (in terms of an integration criterion) for a midrange on an information load continuum. We were here concerned with whether maximum risk taking occurred during optimal or during super- or suboptimal information load conditions.

\section{METHOD}

\section{Subjects and Task}

Fifty-six paid undergraduate volunteers from an Eastern state university were placed into 14 four-man decision-making teams. Ss were instructed to act as equal-rank commanders in a simulated war game situation (the setting is discussed in detail in Streufert et al, 1965). Each team was given the task of making military decisions regarding the invasion of a mythical island. Teams were told that they were playing against another team which supposedly had received instructions to defend the island. All functions of the enemy team were preprogrammed and performed by the Es. Consequences of the Ss' decisions, as determined by the Es, were fed back to the Ss. Information regarding these consequences was slightly favorable at all times. Analysis of a rating scale filled out by the Ss in various phases of the game indicated that they perceived themselves to be in a moderately advantageous position at all times.

Teams were permitted to make any number of decisions they saw fit to make. They were also permitted to make any type of decision, as long as such a decision did not violate the restrictions of the setting (for instance, they could not employ troops beyond the number available to them as stated in the manual ${ }^{2}$ ). The Ss believed that the environment was a direct outcome of their own performance (all Ss indicated on a rating scale that more than $80 \%$ of the ongoing events were, in their opinion, due to their own decisions or decisions of the enemy team rather than to arbitrary causes). Since the environmental conditions were programmed, the kind (not the level) of success experienced by the teams was determined through the constant strategy of the supposed enemy team. In this way teams were kept approximately equal in the general kind of operations employed by them, and in their level of success.

The groups of Ss were required to make all decision on an order form. A separate order form was required for each decision.

The game was played in seven 30 -min periods. During each period, the $\mathrm{Ss}$ were exposed to different information load conditions. During each 30-min game period, Ss received either 2, 5, 8, 10, 12, 15, or 25 independent informative statements. Each statement contained one informative fact relevant to a single operation. These statements would be in response to orders or requests received from the teams of Ss, or, if insufficient orders had been received, the statements would contain an item of general information regarding a "relevant observation."

The order of the load periods was varied. From a number of random sequences those were selected which would insure that each load condition would appear at least once in each position.

Analysis of Decision Making

For the purpose of classification of decisions into types, a graphic representation of the decision sequence was made for each team. The time sequence was plotted horizontally. Types of operations employed by the groups of Ss were listed vertically [e.g., (1) landing troops, (2) reconnaissance, (3) tank attack, (4) retaliatory response, etc.]. In this fashion, each decision made by a team could be represented as a point, placed vertically below the time when it occurred and horizontally beside the type of operation it represented. Points representing the same kind of decisions were connected with horizontal lines. Points representing decisions made at the same point in time were connected with vertical lines. Points representing decisions which led in a planned strategic sequence to later decisions of different kinds were connected with these by diagonal lines. Classification was based on decision texts and statements of relationships given by groups 


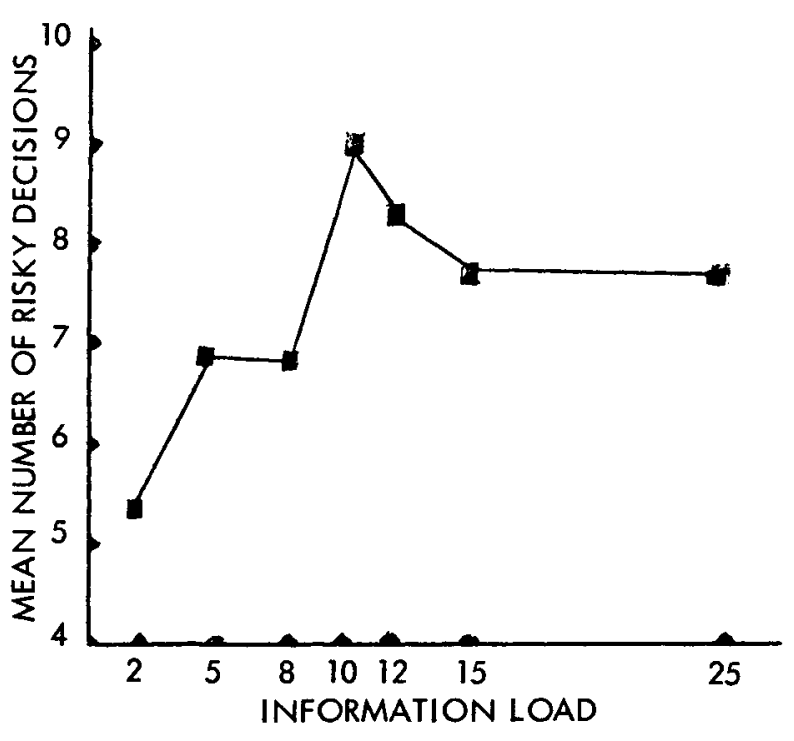

Fig. 1. The effect of information load on risk taking.

of Ss on the decision forms. This graphic representation permitted analysis of decision types as follows:

(1) Risky decisions: All decisions which were aggressive rather than defensive in nature and placed troops or equipment into positions where they were in danger of attack and destruction by enemy forces were defined as risky.

(2) Preparatory decisions: All decisions which were made in anticipation of later aggressive or defensive moves and did not endanger men or equipment were considered nonrisky.

(3) Retaliatory moves: All moves made for defensive purposes in response to information of enemy moves were considered nonrisky.

(4) Withdrawal decisions: All decisions withdrawing men or equipment from endangered positions were considered nonrisky.

All decisions made by the Ss could be classified into these four categories. The number of decisions in Category 1 made during each playing period, ordered by time (for the time analysis) or ordered by increasing information load (for the load analysis), were used as raw data for this experiment. RESULTS

Since the experimental variation of information load was randomized across order (and since partialling out an order effect would merely provide an artificially high level of significance which is unacceptable when measurement of behavior in more "real" environments is at stake), the data were analyzed as two separate within-ANOVA designs. For the load analysis, an F ratio of $7.13(\mathrm{df}=6 / 78 ; \mathrm{p}<.01)$ was obtained. Post hoc Newman-Keuls analysis indicated significant differences between Loads 10 and 12 vs Load $2(p<.01)$ and between Loads 10 and 12 vs Loads 5 and $8(\mathrm{p}<.05)$, as well as between Load 10 and Loads 15 and $25(\mathrm{p}<.05)$. A graphic representation of the results is presented in Fig. 1.

For the analysis of time spent in the simulation (order of periods) an $F$ ratio of $12.35(\mathrm{df}=6 / 78 ; \mathrm{p}<.01)$ was obtained. Newman-Keuls comparison of sequential periods of time spent in the simulation indicated differences for Periods 6 and 7 vs Periods 1, 3, and 4, Period 2 vs Period 1, and Period 5 vs Period 1 $(\mathrm{p}<.01)$. In addition, Period 5 differed from Period 4 $(p<.05)$. These results are graphically shown in Fig. 2.

To check for potential confounding effects of the total number of decisions made by the decision-making groups (cf. Streufert, Driver, \& Haun, 1966), the analysis was repeated for proportions of risky decisions to total number of decisions made by each group in each period. The results remained essentially

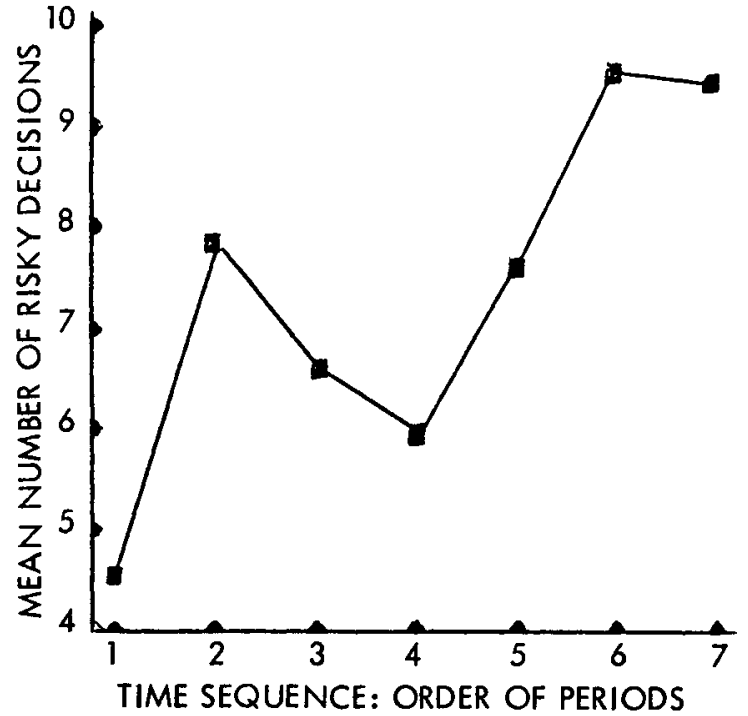

Fig. 2. The effect of time spent in decision making on risk taking.

the same, although the $F$ ratios became slightly smaller [ $F(l o a d)$ $=3.68, \mathrm{p}<.01 ; \mathrm{F}$ (time) $=4.52, \mathrm{p}<.01]$.

\section{DISCUSSION}

The results of the time analysis showed a striking similarity to the work of Davis, Hoppe, \& Hornseth (1968) obtained in a much simpler (gambling) risk experiment. Apparently risk taking increases (although potentially interrupted by a plateau or a dip) with continued participation in a decision-making task.

The increased risk-taking behavior could also be explained as an effect of time spent with a group of others (as might be predicted by theories calling for diffusion of responsibility, value, or censure testing); however, the fact that Davis et al (1968) produced similar results in individuals as well as in groups suggests that such an explanation might be of limited value. The fact that the results of this experiment remained stable even when proportions of risky decisions to total decisions were used as raw data suggests that risky decision making is at least partially independent of the number of decisions made (which also tend toward a general increase over participation time).

An encouraging result was obtained in the analysis of risky decision making as a function of information load. Streufert \& Driver (1965, 1967), Streufert, Driver, \& Haun (1966), Streufert \& Schroder (1965), and Streufert, Suedfeld, \& Driver (1965) have shown that optimal decision-making quality (in terms of a strategy integration criterion) occurs at loads of approximately 10 or 12 independent items of information received by decision makers per $1 / 2 \mathrm{~h}$. It is at this point, as the present analysis indicated, where most risky decisions are made. This result would suggest that risk taking may be more often strategic (probably rational, integrated) rather than respondent (probably retaliatory, unintegrated). This finding suggests that the attempt by several researchers to look for strategies in risky decision making may be of considerable value.

\section{REFERENCES}

BROWN, R. Social psychology. New York: The Free Press, 1965.

COMBS, C. H., \& PRUITT, D. G. Components of risk in decision making: Probability and variance preferences. Journal of Experimental Psychology, 1960, 60, 265-277.

DAVIS, J. H., HOPPE, R. A., \& HORNSETH, J. P. Risk taking: Task, response pattern and grouping. Organizational Behavior \& Human Performance, 1968, 3, 124-142.

(Continured on page 330 ) 
Table 1

Mean Proportion of Collaborative Choices Made by Subjects in Two- and Three-Person Groups Facing the PD Game in Each of Five Trial Blocks

\begin{tabular}{lcccccc}
\hline Group & & \multicolumn{5}{c}{ Trial Block } \\
\hline & 1 & 2 & 3 & 4 & 5 & Mean \\
Two-Person & .44 & .29 & .23 & .28 & .24 & .30 \\
Three-Person & .46 & .39 & .43 & .37 & .54 & .44 \\
Mean & .45 & .35 & .35 & .33 & .41 & .38 \\
\hline
\end{tabular}

\section{DISCUSSION}

The results clearly supported the hypothesis that the presence of a third, advantaged, person would produce more collaboration among two persons playing a PD game than when no third person was present. Moreover, the results with the two-person group are entirely consistent with those of other PD game studies, since, in games with $\mathbf{5 0}$ or fewer trials, it is a common finding that the proportion of noncollaborative choices increases over trials (Gallo \& McClintock, 1965). Hence, it appears that the higher outcomes obtained by the advantaged person restrained the tendency of the two PD game players to make an increasing number of noncollaborative choices over trials.

It is interesting to note, though, that in the three-person situation the two individuals playing the PD game did not, on the whole, settle into a pattern of joint collaboration for more than just one or two trials, even though joint collaboration would permit the players to both maximize their long-run gains and remove the higher outcomes of the advantaged person. Since some people who participated in the three-person situation felt that the long-term consequence of their choices were not clear to them, a simpler method of presenting the outcomes should be developed, if possible. As the outside four cells are not needed to establish the relationships under investigation, a display deleting them could be developed.

It should be possible to investigate many types of three-person interactions by employing the present technique. Not only could the type of interdependent relationship between two of the persons be varied independent of their relationship to the third person, but situations could be developed in which all three individuals were interdependent. This latter situation would then resemble a three-person coalition situation, but would allow for the elimination or control of communication among the group members.

\section{REFERENCES}

BECKER, G. M., \& MCCLINTOCK, C. G. Value: Behavioral decision theory. Annual Review of Psychology, 1967, 18, 107-285.

DEUTSCH, M. Trust and suspicion. Journal of Conflict Resolution, 1958, 2, 265-279.

GAMSON, W. A. Experimental studies of coalition formation. In $\mathbf{L}$. Berkowitz (Ed.), Advances in experimental social psychology. Vol. 1. New York: Academic Press, 1964. Pp. 81-110.

GALLO, P. S., JR., \& McCLINTOCK, C. G. Cooperative and competitive behavior in mixed-motive games. Journal of Conflict Resolution, $1965,9,68-78$.

OSKAMP, S., \& PERLMAN, D. Factors affecting cooperation in a Prisoner's Dilemma game. Journal of Conflict Resolution, 1965, 9, 359-374.

RAPOPORT, A., \& CHAMMAH, A. M. Prisoner's Dilemma: A study in conflict and cooperation. Ann Arbor: University of Michigan Press, 1965.

NOTE

1. This research was supported by a National Aeronautics and Space Administration Traineeship to the first author.
DRIVER, M. J., \& STREUFERT, S. Group composition, input load and group information processing. Purdue University: Institute for Research in the Behavioral, Economic and Management Sciences: Institute Paper No. 142, 1966.

EDWARDS, W. Probability preferences in gambling. American Journal of Psychology, 1953, 66, 349-364.

EDWARDS, W. Probability preferences in gambling. American Journal of Psychology, 1954, 67, 441-452.

KOGAN, N., \& WALLACH, M. A. Risk taking, a study in cognition and personality. New York: Holt, Rinehart, \& Winston, 1964.

PRUITT, D. G. Pattern and level of risk taking in gambling decisions. Psychological Review, 1962, 69, 520-536.

RETTIG, S. Ethical risk taking in group and individual conditions. Journal of Personality \& Social Psychology, 1966, 4, 648-654.

SCHRODER, H. M., DRIVER, M. J., \& STREUFERT, S. Human information processing. New York: Holt, Rinehart, \& Winston, 1967.

STREUFERT, S., CLARDY, M. A., DRIVER, M. J., KARLINS, M., SCHRODER, H. M., \& SUEDFELD, P. A tactical game for the analysis of complex decision making in individuais and groups. Psychological Reports, 1965, 17, 723-729.

STREUFERT, S., \& DRIVER, M. J. Conceptual structure, information load and perceptual complexity. Psychonomic Science, 1965, 3, 249-250.
STREUFERT, S., \& DRIVER, M. J. Impression formation as asmeasure of the complexity of conceptual structure. Educational \& Psychological Measurement, 1967, 27, 1025-1039.

STREUFERT, S., DRIVER, M. J., \& HAUN, K. Components of sresponse rate in complexs decision making. Journal of Experimental Social Psychology, 1967, 3, 286-295.

STREUFERT, S., \& SCHRODER, H. M. Conceptual structure, environmental complexity and task performance. Journal of Experimental Research in Personality, 1965, 1, 132-137.

STREUFERT, $S$., SUEDFELD, P. \& DRIVER, M. J. Conceptual structure, information search and information utilization. Journal of Personality \& Social Psychology, 1965, 2, 736-740.

WALLACH, M. A., KOGAN, N., \& BEM, D. J. Groups influence on individual risk taking. Journal of Abnormal and Social Psychology, $1962,63,75-86$.

\section{NOTES}

1. Research support from the Office of Naval Research, Group Psychology Branch, is gratefully acknowledged.

2. A player's manual for the game is available from American Documentation Institute, Auxiliary Publication Project, Photoduplication Service, Library of Congress, Washington, D. C., Document 8601. 